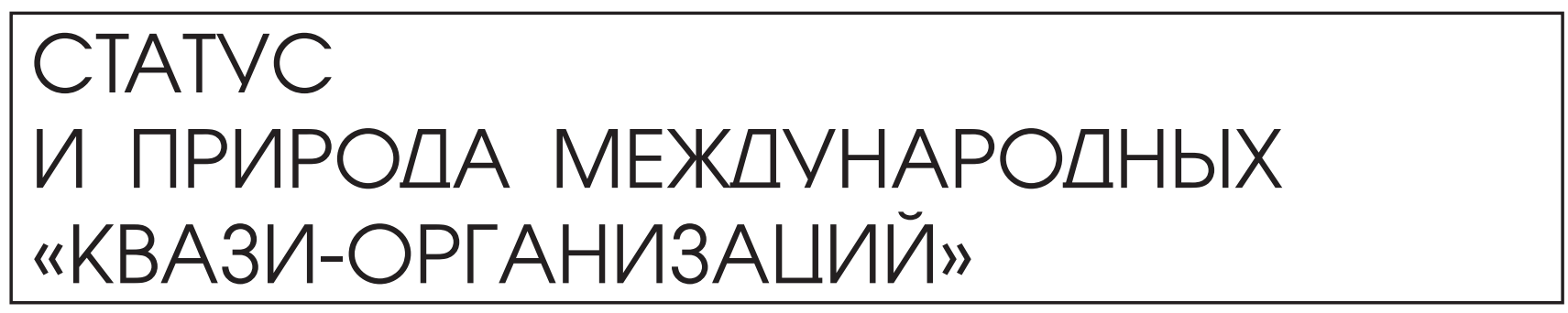

Лобов Д.В.

\title{
АДМИНИСТРАТИВНО-ПРАВОВЫЕ МЕХАНИЗМЫ ОПРЕДЕЛЕНИЯ СТАТУСА ОБСЕ
}

\begin{abstract}
Аннотация. Статья посвящена теоретическим и практическим проблемам организационно-правового обеспечения статуса Организации безопасности и сотрудничества в Европе (ОБСЕ), как особой наднациональной структуры. С применением формально-юридического и сравнительного методов рассмотрены особенности административно-правовой природы ОБСЕ, установленные национальными законодательными актами государств Европь в условиях неопределенности международно-правового статус ОБСЕ. Указано как на применение национальным законодателем международных стандартов иммунитетов для ОБСЕ, так и на случаи создания собственных моделей правового обеспечения статуса ОБСЕ в государствах-участниках. Доказан административно-правовой характер определения статуса ОБСЕ в государствах-участниках, что позволяет корректировать модальность международно-правовых механизмов в сфере мандата ОБСЕ и ее учреждений
\end{abstract}

Ключевые слова: Международное право, административно-правовой статус, ОБСЕ, законодательство об иммунитетах, наднациональные структуры, государства-участники, подзаконные акты, законотворчество, конвениии об иммунитетах, имплементация

Review: The article is devoted to the theoretical and practical problems of organizational and legal guarantees of the OSCE (Organization for Security and Cooperation in Europe), as a special supranational structure. The author uses formal legal and comparative methods in order to evaluate the specific features of administrative and legal nature of the OSCE, as established by the national legislative acts of the states, the international legal status of the OSCE being undetermined. The author points out use of international immunity standards by the states, as well as formation of authentic models for the legal guarantees of the OSCE status in the Member States. The author proves administrative legal character of defining the OSCE status in the Member States, which allows to correct the modality of international legal mechanisms within the framework of the OSCE mandate and its institutions.

Keywords: international law, administrative legal status, OSCE, immunity legislation, supranational structures, by-laws, law-making, immunity conventions, implementation.

еобходимость определения правового статуса ОБСЕ сегодня определяется потребностью установления национальных механизмов сотрудничества с ОБСЕ государств Европы, получения от ОБСЕ экспертной либо технической помощи, реализации в новых независимых государствах мандатов миссий ОБСЕ. Для Украины этот вопрос особо актуален в условиях ее Председательствования в ОБСЕ в 2013 г. Специфика механизмов участия государств в деятельности ОБСЕ обусловлена отсутствием в данной организации устойчивого международно-правового статуса. Неопределенность, возникающая в связи с этим, получает последствия на политическом, институциональном и индивидуальном уровнях.

В связи с данной международно-правовой неопределенностью ряд государств - участников ОБСЕ предоставил ОБСЕ на законодательном уровне привилегии и иммунитеты. Учитывая, что четыре из них являются странами пребывания институтов ОБСЕ (Австрия, Чешская Республика, Нидерланды и Польша) именно их национальное (административное) законодательство имеет для определения статуса ОБСЕ ключевое значение. Его анализ в рамках формально-правовой и 
сравнительной методологии позволит достичь цель нашей работы - установлений модальности и эффективности административно-правовых механизмов определения статуса ОБСЕ. До сих пор соответствующая проблематика в научной литературе не рассматривалась, упоминаясь лишь в отчетной документации органов ОБСЕ.

В первую очередь следует упомянуть о Законе Чешской и Словацкой Федеративной Республики от 5 марта 1992 г. «О создании Секретариата ОБСЕ и привилегиях и иммунитетах Секретариата и других институтов ОБСЕ». Данный акт до сих пор регламентирует статус органов ОБСЕ Чехии и одновременно признается как источник права в Словакии ${ }^{1}$. Согласно закону от 5 марта 1992 г. Секретариат Совещаний по безопасности и сотрудничеству в Европе (СБСЕ) признается юридическим лицом, базирующимся в Праге, при этом на Секретариат и его должностных лиц и административно-технический персонал этим законом распространены привилегии и иммунитеты, указанные в ст.ст. II, III и V Конвенции о привилегиях и иммунитетах Объединенных Наций от 13 февраля 1946 г. (далее - Конвенция 1946 г.)

На делегации государств-участников СБСЕ (ОБСЕ) на конференции, проводимые в Чехии и Словакии в рамках Хельсинкского процесса, а также на делегации государств-участников СБСЕ, прибывших на переговоры в Секретариат СБСЕ (ОБСЕ) данный закон также распространил соответствующие привилегии и иммунитеты, указанные в ст. IV Конвенции 1946 г. На должностных лиц и административно-технический персонал институтов ОБСЕ, имеющих резиденции вне Чехии, указанный закон распространил привилегии и иммунитеты, предусмотренные в ст. VI Конвенции 1946 г. ${ }^{2}$

В отличие от Чехии, в Венгрии национальное законодательство предусмотрело предоставление привилегий не в рамках Конвенции 1946 г., а согласно Конвенции о дипломатических сношениях от

\footnotetext{
${ }^{1} \mathrm{O}$ osobitnom sposobe vratenia sumy dane z pridanej hodnoty viazucej sa na poskytnute zdanitelne plnenie osobam inych statov, ktore pozivaju vyhody podla medzinarodnych zmluv : Vyhlaska Ministerstva financii Slovenskej republiky z 13. oktobra 1993 // Zbierka zakonov. - Sb. 272/1993. - C. 67. - St. 1185.

${ }^{2} \mathrm{O}$ zrizeni Sekretariatu Konference o bezpecnosti a spolupraci v Evrope a o vysadach a imunitach tohoto sekretariatu a dalsich instituci Konference o bezpecnosti a spolupraci v Evrope : Zakon z 5 marca 1992 // Zbierka zakonov. - Sb. 125/1992. - C. 30. - St. 743.
}

18 апреля 1961 г. Так, Закон Венгрии от 18 апреля 1994 г. «О распространении на институты, сотрудников и служащих СБСЕ, представителей государств-участников и членов миссий ОБСЕ привилегий, льгот и иммунитетов, предоставляемых согласно Конвенции о дипломатических сношениях 1961 г. (Вена)» распространил указанные льготы на всех упомянутых в его названии лиц, кроме граждан и постоянных жителей Венгрии.

Как отмечалось в преамбуле Закона от 18 апреля 1994 г. власти Венгрии приняли его в знак подтверждения приверженности своего государства мировым идеалам безопасности, справедливости, дружественных отношений и сотрудничества с целью дальнейшего развития и принимая во внимание возрастающую роль СБСЕ в укреплении доверия между государствами в организации многостороннего сотрудничества и загрузки кризисного управления. При этом отмечалось, что при условии осуществления государствами-участниками СБСЕ, институтами и миссиями ОБСЕ, их сотрудниками собственной деятельности «очень важно, чтобы каждое государство-участник создало правовую основу для таких учреждений, физических лиц и миссий» ${ }^{3}$.

После принятия решения СБСЕ от 21 ноября 1990 г. об учреждении в Варшаве Бюро по свободным выборам СБСЕ Совет Министров Польши постановлением от 2 мая 1991 г. № 65 «О работе Бюро по свободным выборам СБСЕ, расположенное в Варшаве» подтвердил согласие Республики Польша на образование указанного Бюро и распространил на Бюро, его директора, сотрудников, административно-технический персонал и членов их семей льготы, привилегии и иммунитеты, установленные Конвенцией 1946 г. Аналогичные привилегии и иммунитеты были распространены постановлением от 2 мая 1991 г. на членов делегаций для совещаний Бюро, а также на сотрудников Секретариата и Центра по предотвращению конфликтов СБСЕ, прибывавших в Польшу по делам СБСЕ 4 .

\footnotetext{
${ }^{3}$ A diplomaciai kapcsolatokrol Becsben, az 1961. evi aprilis ho 18. napjan kelt szerzodesben biztositott kivaltsagoknak, mentessegeknek es konnyiteseknek az Europai Biztonsagi es Egyuttmukodesi Ertekezlet1 intezmenyeire, tisztsegviseloire es alkalmazottaira, a reszt vevo allamok kepviseloire es az EBEE missziok tagjaira valo kiterjeszteserol : 1994, evi LXXXV torveny. URL : http://www.complex.hu/kzldat/t9400085.htm/t9400085.htm

${ }^{4} \mathrm{~W}$ sprawie dzialania Biura Wolnych Wyborow Konferencji Bezpieczenstwa i Wspolpracy w Europie z siedziba w Warszawie
} 
После решения Совета министров СБСЕ от 31 января 1992 г. в Праге об изменении мандата и названия Бюро по свободным выборам ОБСЕ с образованием Бюро демократических институтов и прав человека (БДИПЛ ОБСЕ), Совета Министров Польши постановлением от 5 июня 1992 г. № 62 «О Бюро по демократическим институтам и правам человека ОБСЕ, расположенном в Варшаве» признал указанные изменения и преемственность БДИПЛ в Польше. Постановление от 2 мая 1991 г. № 65 было отменено и произошла определенная дифференциация иммунитетов: для БДИПЛ, его сотрудников, членов делегаций БДИПл (без упоминания о членах семей) в Польше и далее использовались стандарты Конвенции 1946 г., а для представителей государств-участников СБСЕ и членов их семей (кроме польских граждан) - нормы Конвенции о дипломатических сношениях 1961 г. $^{5}$

Другую конструкцию содержит шведский Закон «О правоспособности институтов ОБСЕ» от 9 июня 1994 г. (1994:717), который затем был инкорпорирован в Закон Швеции 1976 г. «Об иммунитетах, льготах и привилегиях в визовой сфере» (1976:661). В этом акте правосубъектность ОБСЕ признавалась со ссылкой на перечень льгот и иммунитетов, предложенных в ст.ст. 3-16 решения Совета Министров СБСЕ от 1 декабря 1993 г. [257]. Аналогичную правовую конструкцию содержал и Исполнительный указ Президента США № 13029 от 3 декабря 1993 г., которым в правовую систему США было внедрено решение Совета Министров СБСЕ от 1 декабря 1993 г. и инкорпорированы соответствующие предписания в рамках федерального законодательства США об иностранных делах ${ }^{6}$.

Подобный механизм был использован правительством Германии в постановлении от

\footnotetext{
: Uchwala № 65 Rady Ministrow z dnia 2 maja 1991 r. // Monitor Polski. - 1991. - № 16. - P. 142. - Poz. 106.

${ }^{5} \mathrm{~W}$ sprawie Biura Instytucji Demokratycznych i Praw Człowieka Konferencji Bezpieczeństwa i Współpracy w Europie z siedzibą w Warszawie : Uchwala № 62 Rady Ministrow z dnia dnia 5 czerwca 1992 r. // Monitor Polski. - 1992. - № 16. - P. 182. - Poz. 118.

${ }^{6}$ Implementing, for the United States, the Provisions of Annex 1 of the Decision Concerning Legal Capacity and Privileges and Immunities, Issued by the Council of Ministers of the Conference on Security and Cooperation in Europe on December 1, 1993 : Executive Order 13029 of December 3, 1996 // Federal Register. - 1996. - December 5. - Vol. 61. - № 235. - PD 64591.
}

15 февраля 1996 г. «О привилегиях и иммунитетах ОБСЕ» (с изменениями от 22 сентября 2005 г.). В п. 1 этого постановления за ОБСЕ в Германии в целом признавались привилегии и иммунитеты, указанные в решении Совета министров СБСЕ от 1 декабря 1993 г. Эти положения признавались для Секретариата ОБСЕ, БДИПЛ ОБСЕ и для Управления Верховного комиссара по делам национальных меньшинств (ВКНДМ) ОБСЕ и частично для Парламентской ассамблеи ОБСЕ, при этом в постановлении от 15 февраля 1996 г. содержались определенные ограничения иммунитетов, перечисленных в решении от 1 декабря 1993 г. Интересно, что в преамбуле к постановлению от 15 февраля 1996 г. правовой основой для его одобрения определялась Конвенция о привилегиях и иммунитетах специализированных учреждений от 21 ноября 1947 г., которая не имеет в принципе никакого отношения к ОБСЕ и ее институтам ${ }^{7}$.

Впервые в Австрии статус СБСЕ был определен Федеральным законом «О предоставлении привилегий и иммунитетов Центра по предотвращению конфликтов ОБСЕ, его служащим и другим сотрудникам, работающим в учреждениях в рамках СБСЕ» № 339 от 1 февраля 1991 г. Согласно этому акту было Австрией была признана правосубъектность Центра по предотвращению конфликтов ОБСЕ, при этом Центру и его сотрудникам были предоставлены привилегии и иммунитеты в той же мере, как и органам $\mathrm{OOH}$ в Вене и их сотрудникам на основе существующих договоров. Должностным лицам Секретариата ОБСЕ и Бюро по свободным выборам ОБСЕ, находившимся при исполнении своих функций в Австрии, законом 1991 г. предоставлялись привилегии и иммунитеты в той же мере, как и экспертам, работающих по заказу ООН в Вене по контракту ${ }^{8}$.

На примере этих документов можно увидеть, что национальные административно-правовые

\footnotetext{
${ }^{7}$ Verordnung uber Vorrechte und Immunitaten der Organisation fur Sicherheit und Zusammenarbeit in Europa (OSZE), OSZEVorRV6, 15 Februar 1996. URL : http://www.gesetze-iminternet.de/bundesrecht/oszevorrv/gesamt.pdf

${ }^{8}$ Bundesgesetz uber die Einraumung von Privilegien und Immunitaten an das KSZEKonfliktverhutungszentrum, seine Bediensteten und die Bediensteten anderer standiger Einrichtungen im Rahmen der KSZE (NR: GP XVIII RV 97 AB 155 S. 29. BR: AB 4062 S. 542.). URL : http://www.ris.bka.gv.at/Dokumente/ BgblPdf/1991_339_0/1991_339_0.pdf
} 
механизмы, устанавливая систему льгот и привилегий для субъектов СБСЕ (ОБСЕ), прямо использовали международные документы о льготах и привилегиях различного характера и содержания, как образец для национальной практики. Впрочем, в других государствах административное законодательство о статусе ОБСЕ шло в определенной степени другим путем - через внедрение аутентичных административно-правовых механизмов в этой сфере. Характерным примером такого регулирования стал закон Италии от 30 июля 1998 г. № 301 «О правоспособности учреждений ОБСЕ и связанных с этим привилегиях и иммунитетах»".

В ст. 1 Закона от 30 июля 1998 г. отмечалось, что Италия признает правоспособность, необходимую для осуществления своих функций и возможность заключать договоры, приобретать и распоряжаться движимым и недвижимым имуществом, участвовать в судебных разбирательствах, для таких учреждений ОБСЕ, как Секретариат и БДИПЛ ОБСЕ и одновременно для «любых других институтов ОБСЕ, которые будут определены, как таковые, Советом министров ОБСЕ, с публикацией решений о них в официальном бюллетене Итальянской Республики в пресс-релизе, подготовленном МИД».

Согласно ст. 2 указанного Закона от привилегий и иммунитетов для института ОБСЕ Генеральный секретарь ОБСЕ может отказаться после консультации с действующим председателем ОБСЕ. Специально отмечается, что привилегии и иммунитеты предоставляются соответствующим представителям ОБСЕ не для их личной выгоды, а для обеспечения их независимости при исполнении своих обязанностей. Решение об отказе от иммунитета разрешается для снятия препятствий для осуществления правосудия, оно принимается и от него можно отказаться без ущерба для той цели, ради которого иммунитет был предоставлен. При этом соответствующее правительство может отказаться от иммунитета в отношении своих представителей в ОБСЕ.

Согласно ст. 3 указанного Закона институты ОБСЕ, действующие в Италии, их имущество и

\footnotetext{
${ }^{9}$ Disposizioni concernenti la capacita giuridica delle istituzioni dell'Organizzazione per la sicurezza e la cooperazione in Europa (OSCE) ed i relativi privilegi ed immunita : Legge 30 luglio 1998, n. 301 // Gazzetta Ufficiale. - 1998. - n. 196. - 24 agosto. - P. 5.
}

финансовые активы, находящиеся на итальянской территории, пользуются иммунитетом от судебного преследования и не предоставляются иностранным государствам. Собственность институтов ОБСЕ в Италии признается неприкосновенной, имущество и денежные средства институтов ОБСЕ, расположенных на территории Италии, освобождаются от обыска, реквизиции, конфискации и экспроприации. Архивы институтов ОБСЕ в Италии также признаются неприкосновенными.

Согласно предписаниям ст. 6 Закона 1998 г. должностные лица ОБСЕ в Италии, а именно Генеральный секретарь, Верховный комиссар по делам национальных меньшинств и лица, занимающие должности, указанные компетентным органом, который принимает решения в ОБСЕ или назначенные им (кроме граждан или постоянных жителей Италии) пользуются такими привилегиями и иммунитетами:

- иммунитетом от судебного преследования в отношении деятельности, в том числе действий и высказываний, при выполнении своих функций;

- личным освобождением для супругов и иждивенцев от ограничений по иммиграции и от формальностей по регистрации иностранцы, аналогичное освобождению дипломатических агентов;

- проведением операций с иностранной валютой в порядке, установленном для дипломатических агентов;

- предоставлением репатриации во время международных кризисов для должностного лица, его супруги и иждивенцев, в порядке, установленном для дипломатических агентов;

- правом однократно ввозить беспошлинно собственные мебель и личные вещи при обустройстве на работе в Италии и вывозить их беспошлинно при оставлении офиса ОБСЕ.

Кроме того, сотрудники институтов ОБСЕ освобождаются от системы программ социального обеспечения в Италии до тех пор, как они получают социальное страхование в государстве происхождения или если они защищены программой социального обеспечения институтов ОБСЕ либо иной аналогичной программой ${ }^{10}$.

За ОБСЕ Закон Италии 1998 признает право предоставлять удостоверение личности ОБСЕ для

\footnotetext{
${ }^{10}$ Там же.
} 
лиц, передвигающихся для выполнения официальных обязанностей ОБСЕ (в приложении к закону содержится описание такого удостоверения. Этот документ выдается на шести официальных языках ОБСЕ и содержит перевод на язык (языки) страны (стран) обладателя документа, и перевод на язык (языки), которые используются военными или полицейскими в регионе поездки.

Другим примером национального административно-правового обеспечения статуса и деятельности ОБСЕ можно считать Федеральный закон Австрии «О статусе институтов ОБСЕ в Австрии» от 30 июля 1993 г. в текущей редакции. Согласно $\S 1$ настоящего Закона учреждения ОБСЕ, базирующиеся в Австрии, признаются в Австрии юридическими лицами, перечень этих учреждений публикует Федеральный министр иностранных дел в Бюллетене федеральных законов. В частности, в Бюллетене № 511/1993 были упомянуты такие учреждения как Генеральный секретарь ОБСЕ, Управление Генерального секретаря ОБСЕ, Группа Венского Комитета старших должностных лиц, Форум СБСЕ по сотрудничеству в области безопасности, его Исполнительный секретариат, Центр предотвращения конфликтов ОБСЕ, Совместная консультативная группа по Договору об обычных вооруженных силах в Европе и Консультативная Комиссия по Соглашению об открытом небе [256]. Власти Австрии были обязаны в силу § 2 Закона от 30 июля 1993 г. исполнять все решения и соглашения ОБСЕ направленные на достижение задач этой организации ${ }^{11}$.

Должностные лица и сотрудники указанных структур ОБСЕ, согласно § 5а указанного закона были освобождены от австрийских обязательных институтов социального страхования, с сохранением за ними права добровольного медицинского страхования в Австрии, причем Закон от 30 июля 1993 г. (в редакции Закона от 1 июня 2002 г.) детально регламентирует порядок и правовые последствия такого страхования служащих ОБСЕ. Формат удостоверений ОБСЕ

\footnotetext{
${ }^{11}$ Bundesgesetz uber die Rechtsstellung von Einrichtungen der OSZE in Osterreich, «OSZE-Gesetz» (30 Juli 1993), [BGB1. Nr. 511/1993 durch das Bundesgesetz BGB1. Nr. 735/1995 und durch das Bundesgesetz BGBL. 157/2002 geandert]. URL : http://www.ena.lu/bundesgesetz_uber_rechtsstellung_einrichtungen_osze_osterreich_juli_1993_konsolidierte_version_2002-03-21920
}

в Австрии согласно приведенному Законом устанавливается Федеральным министром иностранных дел (§ 7).

Примером достаточно детальной административно-правовой регламентации статуса и деятельности институтов ОБСЕ также следует считать Закон Нидерландов от 31 октября 2002 г., «О правовом статусе, привилегиях и иммунитетах ВКДНМ». Этот закон был принят, «учитывая целесообразность ВКДНМ, как института ОБСЕ» учитывая тот факт, что местом постоянного пребывания ВКДНМ решениями ОБСЕ была избрана Гаага. Этот закон содержит признание и определения Управления ВКДНМ и самого ВКДНМ, должностных лиц Управления, их официальных функций (как задач и мероприятий, вытекающих из мандата ВКДНМ, принятого ОБСЕ), должностных лиц ОБСЕ, статус экспертов ВКДНМ и ОБСЕ, статус домов и участков, используемых ВКДНМ, медиа ВКДНМ и статуса членов семьи ВКДНМ ${ }^{12}$.

При этом в ст. 2 закона 2002 г. ВКДНМ признается юридическим лицом, а ОБСЕ рассматривается как международная организация, частью которой является ВКДНМ. Основным принципом Закона от 31 октября 2002 г. является то, привилегии и иммунитеты для ВКДНМ признаются Нидерландами в той же степени как и для других международных организаций или их институтов. В законе 2002 г. отмечается, что архивы ВКСНМ неприкосновенны, а все имущество ВКДНМ, связанное с осуществлением им официальных функций не может подлежать обыску, изъятию, уголовном и гражданском ареста, конфискации или экспроприации.

Согласно ст.ст. 8, 9 указанного закона в рамках исполнения своих служебных обязанностей ВКДНМ и его имущество освобождаются от всех прямых налогов, взимаемых в Нидерландах на национальном, региональном или местном уровне, в частности, от таможенной пошлины, налога на добавленную стоимость, страхового налога и т.д. Также ВКДНМ не подлежит в Нидерландах финансовому контролю и, в рамках выполнения своих служебных обязанностей, может свободно

\footnotetext{
${ }^{12}$ Wet van 31 oktober 2002, houdende bepalingen inzake rechtspersoonlijkheid, privileges en immuniteiten van de Hoge Commissaris inzake Nationale Minderheden (Wet HCNM). URL : http://www.st-ab.nl/wetten/0528 Wet HCNM.htm
} 
обменивать денежные средства, распоряжаться ими, иметь счета, делать их переводы и т.д.

Следует отметить, что отдельные государстваучастники ОБСЕ, в отличие от вышеуказанных, предоставляя фактически ОБСЕ привилегии и иммунитеты, не закрепляют это в национальном праве, либо осуществляют такое закрепление вне рамок принятия специального правового акта. Так, в своем ответе ОБСЕ по этому поводу Дания отметила, что «правительство Дании может осуществлять положения [решение Римской встречи Совета] с помощью административных мер на основе существующего законодательства» и уточнила, что, «для того чтобы предоставлять привилегии и иммунитеты представителям государств- участников, должностным лицам и членам миссий, необходимо, чтобы правительство получало адекватную информацию о них до прибытия делегаций в Данию» ${ }^{13}$.

В свою очередь Норвегия в ответе на аналогичный запрос ОБСЕ указала в 1994 г., что после принятия поправки к закону о привилегиях и иммунитетах международных организаций правительство получило полномочия «при определенных условиях предоставлять международным организациям привилегии и иммунитеты также в случаях, когда между Норвегией и соответствующей организацией не заключено соглашения, которое согласно международному праву имеет обязательную силу», и таким образом в Норвегии были сняты правовые препятствия для фактического признания правосубъектности, привилегий и иммунитетов ОБСЕ ${ }^{14}$.

Добавим, что несовершенство национальных правовых механизмов обеспечения деятельности ОБСЕ обусловливает законопроектную работу в этой сфере. Например, в Польше правительством долгое время разрабатывались проекты закона, направленного на регулирование правоспособности и привилегий и иммунитетов институтов ОБСЕ, который заменил бы указанное выше устаревшее постановление № 65 от 5 июня 1992 г. В частности, можно указать на два таких законопроекта,

\footnotetext{
${ }^{13}$ Доклад Совету Министров о правоспособности, привилегиях и иммунитетах ОБСЕ : решение Постоянного совета № 383 от 26 ноября 2000 г. PC.DEC/383, PC Journal № 312, п. 1 повестки дня. URL : www.osce.org/ru/mc/40504

14 Там же.
}

разработанные Законодательной Радой (которая в Польше является консультативно-совещательным органом при Совете Министров) и МИД Польши: законопроект Законодательной Рады 2002 г. «О БДИПЧ ОБСЕ и Секретариате Сообщества демократий» и законопроект «Об отдельных организационных подразделениях международных структур», разработанный МИД Польши ${ }^{15}$.

Следует отметить, что кроме формы обеспечения статуса, привилегий и иммунитетов ОБСЕ на национальном уровне путем принятия национальных административных нормативных актов, ряд государств-участников ОБСЕ избрал другой формат, а именно заключение двусторонних соглашений с ОБСЕ, в которых определялись особенности деятельности этой организации в конкретном государстве. Такие соглашения обычно имеют название Меморандумов о взаимопонимании и принимаются, как правило, с государствами, в которых планируется или уже действует миссия ОБСЕ в соответствии с мандатом, одобренном решением руководящих органов ОБСЕ.

Изучив особенности национального административно-правового обеспечения статуса ОБСЕ в государствах-участниках, следует указать, что данный статус устанавливается различными путями: через одобрение специальных актов национального законодательства об ОБСЕ (которые по содержанию являются административноправовыми), путем подписания двусторонних меморандумов с ОБСЕ и его органами и в рамках применения административных механизмов и процедур без заключения соглашений либо принятия законодательных актов. Принятие специальных актов административного законодательства об ОБСЕ состоялось прежде всего в государствах, где расположены главные институты ОБСЕ и потребность в регламентации их деятельности стала наиболее острой (это Австрия, Нидерланды, Польша и Чехия). Их изучение, как правового регулятора, может стать предметом дополнительных исследований в условиях декларируемой потребности пересмотра международно-правового статуса ОБСЕ.

\footnotetext{
${ }^{15}$ Ustawa z dnia ... o Biurze Instytucji Demokratycznych i Praw Czlowieka Organizacji Bezpieczenstwa i Wspolpracy w Europie oraz o Sekretariacie Wspolnoty Demokracji. : Projekt Rady Legislacyjnoy. URL : http://www.radalegislacyjna.gov.pl/ userfiles/RL-0303-29_09us.pdf
} 


\section{Библиография (References):}

1. Доклад Совету Министров о правоспособности, привилегиях и иммунитетах ОБСЕ : решение Постоянного совета № 383 от 26 ноября 2000 г. PC.DEC/383, PC Journal № 312, п. 1 повестки дня. URL : www.osce.org/ru/mc/40504

2. A diplomaciai kapcsolatokrol Becsben, az 1961. evi aprilis ho 18. napjan kelt szerzodesben biztositott kivaltsagoknak, mentessegeknek es konnyiteseknek az Europai Biztonsagi es Egyuttmukodesi Ertekezlet1 intezmenyeire, tisztsegviseloire es alkalmazottaira, a reszt vevo allamok kepviseloire es az EBEE missziok tagjaira valo kiterjeszteserol : 1994, evi LXXXV torveny. URL : http://www.complex.hu/kzldat/t9400085. $\mathrm{htm} / \mathrm{t} 9400085 . \mathrm{htm}$

3. Bundesgesetz uber die Einraumung von Privilegien und Immunitaten an das KSZE Konfliktverhutungszentrum, seine Bediensteten und die Bediensteten anderer standiger Einrichtungen im Rahmen der KSZE (NR: GP XVIII RV 97 AB 155 S. 29. BR: AB 4062 S. 542.). URL : http://www.ris.bka.gv.at/Dokumente/ BgblPdf/1991_339_0/1991_339_0.pdf

4. Bundesgesetz uber die Rechtsstellung von Einrichtungen der OSZE in Osterreich, «OSZE-Gesetz» (30 Juli 1993), [BGB1. Nr. 511/1993 durch das Bundesgesetz BGB1. Nr. 735/1995 und durch das Bundesgesetz BGBL. 157/2002 geandert]. URL : http://www.ena.lu/bundesgesetz_uber_rechtsstellung_einrichtungen_osze_osterreich_juli_1993_konsolidierte_version_2002-03-21920

5. Disposizioni concernenti la capacita giuridica delle istituzioni dell'Organizzazione per la sicurezza e la cooperazione in Europa (OSCE) ed i relativi privilegi ed immunita : Legge 30 luglio 1998, n. 301 // Gazzetta Ufficiale. - 1998. - n. 196. -24 agosto. - P. 5.

6. Implementing, for the United States, the Provisions of Annex 1 of the Decision Concerning Legal Capacity and Privileges and Immunities, Issued by the Council of Ministers of the Conference on Security and Cooperation in Europe on December 1, 1993 : Executive Order 13029 of December 3, 1996 // Federal Register. - 1996. - December 5. - Vol. 61. - № 235. - PD 64591.

7. O osobitnom sposobe vratenia sumy dane z pridanej hodnoty viazucej sa na poskytnute zdanitelne plnenie osobam inych statov, ktore pozivaju vyhody podla medzinarodnych zmluv : Vyhlaska Ministerstva financii Slovenskej republiky z 13. oktobra 1993 // Zbierka zakonov. - Sb. 272/1993. - C. 67. - St. 1185.

8. O zrizeni Sekretariatu Konference o bezpecnosti a spolupraci v Evrope a o vysadach a imunitach tohoto sekretariatu a dalsich instituci Konference o bezpecnosti a spolupraci v Evrope : Zakon z 5 marca 1992 // Zbierka zakonov. - Sb. 125/1992. - C. 30. - St. 743.

9. Ustawa z dnia ... o Biurze Instytucji Demokratycznych i Praw Czlowieka Organizacji Bezpieczenstwa i Wspolpracy w Europie oraz o Sekretariacie Wspolnoty Demokracji. : Projekt Rady Legislacyjnoy. URL : http://www.radalegislacyjna.gov.pl/userfiles/RL-0303-29_09us.pdf

10. Verordnung uber Vorrechte und Immunitaten der Organisation fur Sicherheit und Zusammenarbeit in Europa (OSZE), OSZEVorRV6, 15 Februar 1996. URL : http://www.gesetze-im-internet.de/bundesrecht/ oszevorrv/gesamt.pdf

11. W sprawie Biura Instytucji Demokratycznych i Praw Człowieka Konferencji Bezpieczeństwa i Współpracy w Europie z siedzibą w Warszawie : Uchwala № 62 Rady Ministrow z dnia dnia 5 czerwca 1992 r. // Monitor Polski. - 1992. - № 16. - P. 182. - Poz. 118.

12. W sprawie dzialania Biura Wolnych Wyborow Konferencji Bezpieczenstwa i Wspolpracy w Europie $z$ siedziba w Warszawie : Uchwala № 65 Rady Ministrow z dnia 2 maja 1991 r. // Monitor Polski. - 1991. № 16. - P. 142. - Poz. 106.

13. Wet van 31 oktober 2002, houdende bepalingen inzake rechtspersoonlijkheid, privileges en immuniteiten van de Hoge Commissaris inzake Nationale Minderheden (Wet HCNM). URL : http://www.st-ab.nl/wetten/0528_Wet_HCNM.htm 